\title{
Reducing neonatal deaths in South Africa: Progress and challenges
}

\author{
N R Rhoda, ${ }^{1}$ MB ChB, FCPaed, Certificate in Neonatology; S Velaphi, ${ }^{2}$ MB ChB, FCPaed; G S Gebhardt, ${ }^{3}$ MB ChB, MMed, MSc (MedSci), \\ FCOG, PhD; S Kauchali, ${ }^{4}$ FCPaed, MS, MPhil; P Barron, ${ }^{5}$ FFCH

\begin{abstract}
Department of Neonatology and Paediatrics, Faculty of Health Sciences, University of Cape Town, South Africa
${ }^{2}$ Department of Paediatrics, School of Clinical Medicine, Faculty of Health Sciences, University of the Witwatersrand, Johannesburg, South Africa

${ }^{3}$ Department of Obstetrics and Gynaecology, Faculty of Health Sciences, Stellenbosch University, Stellenbosch, and Tygerberg Hospital, South Africa

${ }^{4}$ National Department of Health, South Africa, and Department of Paediatrics and Child Health, University of KwaZulu-Natal, Durban, South Africa

${ }^{5}$ School of Public Health, University of the Witwatersrand, Johannesburg, South Africa
\end{abstract}

Corresponding author: N R Rhoda (natasha.rhoda@uct.ac.za)

\begin{abstract}
Although current levels of the neonatal mortality rate (NMR) are within reach of the Sustainable Development Goal (SDG) target of 12 per 1000 live births, the absolute number of deaths is unacceptably high for a lower-middle-income country such as South Africa (SA). Neonatal mortality over the last decade has declined very slowly, and is not commensurate with the level of government investment in healthcare. The recent neonatal mortality rate of 21 per 1000 live births reported by the SA Demographic Health Survey is of major concern. This paper reviews recent efforts to reduce the neonatal mortality rate, including support for the implementation of neonatal policies and plans, and strengthening programmes to deliver low-cost, high-impact interventions. We review recent estimates of the NMR and causes of neonatal deaths, and discuss how the mortality from preventable causes of death could be reduced. If SA is to meet the SDG target, special attention should be given to the availability of high-impact interventions, providing an adequate number of appropriately trained healthcare providers and a more active role played by ward-based community health workers and district clinical specialist teams.
\end{abstract}

S Afr Med J 2018;108(3 Suppl 1):S9-S16. DOI:10.7196/SAMJ.2018.v108i3.12804

In 2005, about 4 million newborns died worldwide, ${ }^{[1]}$ with more than $80 \%$ of the deaths occurring in lower-middle-income countries in sub-Saharan Africa and South Asia. ${ }^{[2]}$ Since the Millennium Development Goals project ended in 2015, the annual reduction rate in mortality was noted to be slower during the neonatal period than in the post-neonatal period ( 1 - 59 months): $3.1 \%$ v. $4.7 \%$, with a subsequent increase in the proportion of neonatal deaths accounting for $45 \%$ of the global under-5 mortality rate. ${ }^{[3]}$ The United Nations Inter-agency group for child mortality reported that the global neonatal mortality rate (NMR) fell from 36 per 1000 live births to 19 per 1000 live births. This translates to a $47 \%$ reduction in neonatal deaths, to 2.7 million deaths per year, for the 2005 - 2015 period. ${ }^{[4]}$

Many lower-middle-income countries have unreliable measurements and estimates of neonatal mortality. In-country vital statistics data that counts every birth and death, coupled with an accurate cause of death, is necessary for decision-making, planning and resource allocation. In most African countries, fewer than 25\% of deaths are registered, with only $2 \%$ of African and Asian countries having complete data. ${ }^{[5]}$ South Africa (SA) is an exception, and it is one of the few sub-Saharan African countries that has varied and rich sources of mortality data for children. These are shown in Table 1.

This article reviews recent estimates of the NMR and causes of neonatal deaths in SA. It also reviews the strategies that are being used to reduce the NMR. In order to reach and surpass the sustainable development target for the NMR, we propose approaches to accelerate the rate of reduction of neonatal mortality resulting from preventable causes of death.

\section{Methods}

The NMRs for the period 2012 - 2015 were analysed using a number of data sources. Routine data were extracted from the District Health
Information System (DHIS), the routine information system used by the public health sector in SA. The DHIS does not report on neonatal deaths occurring in private sector healthcare facilities or those that occur outside of the healthcare system. These data were compared with the Rapid Mortality Surveillance (RMS) reports ${ }^{[6-9]}$ produced by the Medical Research Council (MRC) annually. The RMS reports are based on a detailed analysis of the relevant death reports from the vital statistics of Statistics SA (StatsSA) ${ }^{[1,111]}$ The DHIS data were also compared with two facility audit tools completed by hospital clinicians following mortality review meetings (the Perinatal Problem Identification Programme and the Child Problem Identification Programme (PPIP and Child PIP)). Further data on population dynamics were obtained from the SA Demographic Health Survey ${ }^{[12-14]}$ (SADHS) carried out by the MRC and the National Department of Health $(\mathrm{NDoH})$. The rates are reported as number of deaths per 1000 live births. The two audit programmes generate the Saving Babies ${ }^{[15-23]}$ and Saving Children ${ }^{[24-30]}$ reports, respectively.

\section{Results}

\section{Neonatal mortality rates and numbers}

In combining the data from the DHIS and RMS reports, the resulting mortality rates in SA from 2002 to 2015 are shown in Fig. 1 . This shows that the under- 5 mortality rate rapidly declined from a peak of 80 per 1000 at the height of the AIDS epidemic in 2003 - 2005, to 41 per 1000 in 2012, with a slow decrease thereafter to 37 per 1000 live births in 2015. The NMR has remained the same, at $11-12$ per 1000 live births between 2012 and 2015. In 2015, the NMR in SA accounted for $44 \%$ of the infant mortality rate (27 per 1000 live births), and $32 \%$ of the under-5 mortality rate (37 per 1000 live births), respectively. ${ }^{[6]}$

Data from the DHIS for 2016 show that the NMR was 12.6 per 


\begin{tabular}{|c|c|c|c|}
\hline Data source & Advantages & Limitations & Report generated from data \\
\hline $\begin{array}{l}\text { National Population } \\
\text { Register. Department of } \\
\text { Home Affairs, SA. }\end{array}$ & Allows for trends to be monitored. & $\begin{array}{l}\text { Only includes deaths of individuals with } \\
\text { an SA birth certificate or identification } \\
\text { document. }\end{array}$ & Rapid Mortality Surveillance. $^{[6-9]}$ \\
\hline $\begin{array}{l}\text { Vital Registration. Statistics } \\
\text { South Africa. }\end{array}$ & $\begin{array}{l}\text { Records all births and deaths in } \\
\text { public and private. }\end{array}$ & Data has a 2-year lag phase. & $\begin{array}{l}\text { Perinatal Health Report by } \\
\text { Statistics South Africa. }{ }^{10,11]}\end{array}$ \\
\hline $\begin{array}{l}\text { District Health Information } \\
\text { System. NDoH. }\end{array}$ & $\begin{array}{l}\text { Records all births and deaths } \\
\text { occurring in the public and (where } \\
\text { recorded) private health sectors. }\end{array}$ & $\begin{array}{l}\text { Collects data on both early and late } \\
\text { deaths; although late deaths are not } \\
\text { consistently reported. }\end{array}$ & $\begin{array}{l}\text { Routine DHIS data reports. } \\
\text { Annual Report of NDoH. } \\
\text { NDoH Annual Performance } \\
\text { Plan (not available to public). }\end{array}$ \\
\hline $\begin{array}{l}\text { Demographic Health } \\
\text { Survey. }\end{array}$ & $\begin{array}{l}\text { Provides population-based } \\
\text { demographic information that } \\
\text { contributes to the understanding of } \\
\text { population dynamics. }\end{array}$ & Only carried out every 5 years. & $\begin{array}{l}\text { South African Demographic } \\
\text { Health Survey (SA-DHS). }{ }^{[12-14]}\end{array}$ \\
\hline $\begin{array}{l}\text { Perinatal Problem } \\
\text { Identification Programme. }\end{array}$ & $\begin{array}{l}\text { Records primary obstetric and final } \\
\text { neonatal cause of death. } \\
\text { Documents the avoidable causes } \\
\text { of death. } \\
\text { Records all births in weight } \\
\text { categories. } \\
\text { Validation checks inbuilt. }\end{array}$ & $\begin{array}{l}\text { Collected on voluntary basis by enthusiast } \\
\text { doctors. } \\
\text { Represents only } 77 \% \text { of the DHIS data. }\end{array}$ & Saving Babies Report. ${ }^{[15-23]}$ \\
\hline $\begin{array}{l}\text { Child Problem } \\
\text { Identification Programme. }\end{array}$ & $\begin{array}{l}\text { Records all late neonatal deaths } \\
\text { occurring in paediatric and } \\
\text { emergency wards. }\end{array}$ & $40 \%$ of hospitals do not submit data. & Saving Children Report. ${ }^{[2-30]}$ \\
\hline
\end{tabular}

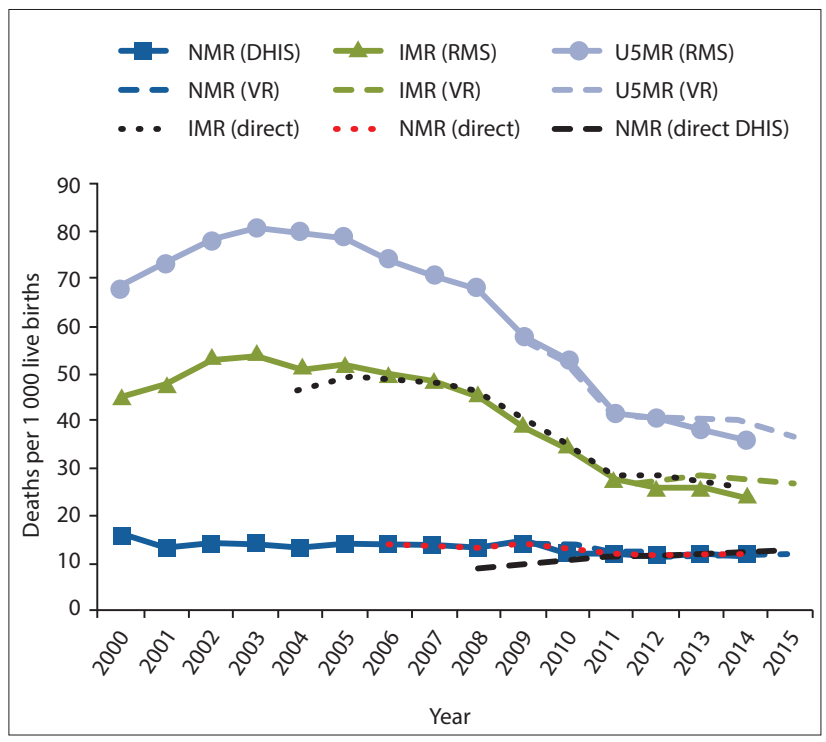

Fig. 1. SA mortality rates $2002-2015(N M R=$ neonatal mortality rate; $I M R=$ infant mortality rate; $U 5 M R=$ under -5 mortality rate; $R M S=$ Rapid Mortality Surveillance; $V R=$ vital registration $;$ DHIS $=$ District Health Information System).

1000 live births, and the early and late neonatal mortality rates were 10.2 and 2.4 per 1000 live births, respectively. The majority (81\%) of neonatal deaths in 2016 occurred in the first week of life.

The individual provincial DHIS data for 2012 - 2016 are shown in Fig. 2. There was an increase in the total number of early neonatal deaths in the Gauteng, KwaZulu-Natal (KZN) and Western Cape provinces when comparing deaths in 2013 with the subsequent years. Late neonatal deaths increased by $17 \%$, from 1 793 deaths (1.9 per 1000 ) in 2012 to 2101 (2.4 per 1000$)$ in 2016.

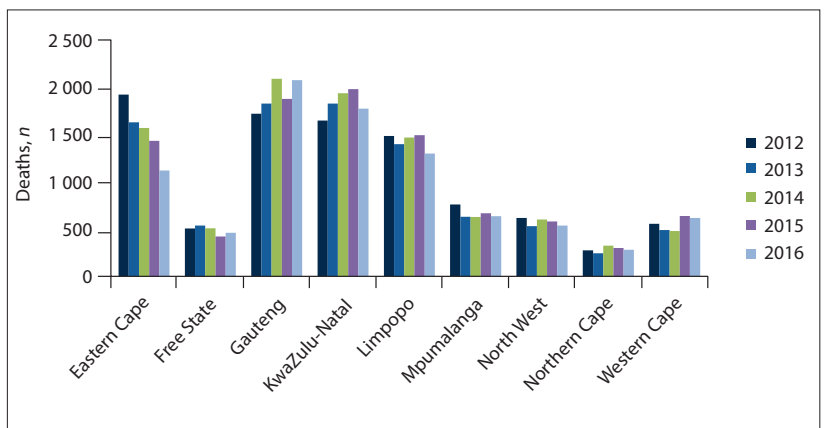

Fig. 2. Provincial early neonatal deaths, 2012 - 2016.

Recently, the SADHS reported a neonatal mortality rate of 21 per 1000 live births for 2016, which is higher than the rate reported by the DHIS. ${ }^{[12]}$

\section{Causes of death}

The 2016 PPIP data show that the main causes of all neonatal deaths (birth weight $\geq 500$ grams) are complications of prematurity (47.9\%); intrapartum-related events, mainly intrauterine hypoxia (24.3\%); and infections (including pneumonia, at 11.6\%) (Fig. 3). A total of $60 \%$ of the premature deaths was accounted for by extreme low birth weight (ELBW) babies (birth weight $<1000$ grams), who die primarily of extreme organ immaturity. If one excludes ELBW infants from the deaths when assessing the causes of death for the period under review, deaths due to intrapartum-related events supersede the complications of preterm births in babies weighing $\geq 1000$ grams.

A comparison of cause-specific mortality over three 5-year cohorts, excluding ELBW infants, reflects this picture (Fig. 4).

Following the Every Newborn Counts global campaign, ${ }^{[31]}$ which advocates the counting of every newborn death, Fig. 5 shows the 
calculated number of early neonatal deaths per cause of death per level of care from PPIP, with adjustment using the DHIS numbers (R Pattison, unpublished research, 2017). At district hospital level, where most babies are born, there is also the highest burden of premature deaths and intrapartum-related injuries. Infection and congenital abnormalities are the 3rd and 4th most common causes of early neonatal deaths, respectively. The overall picture of late neonatal deaths is uncertain, as very few of these deaths are captured by the current databases.

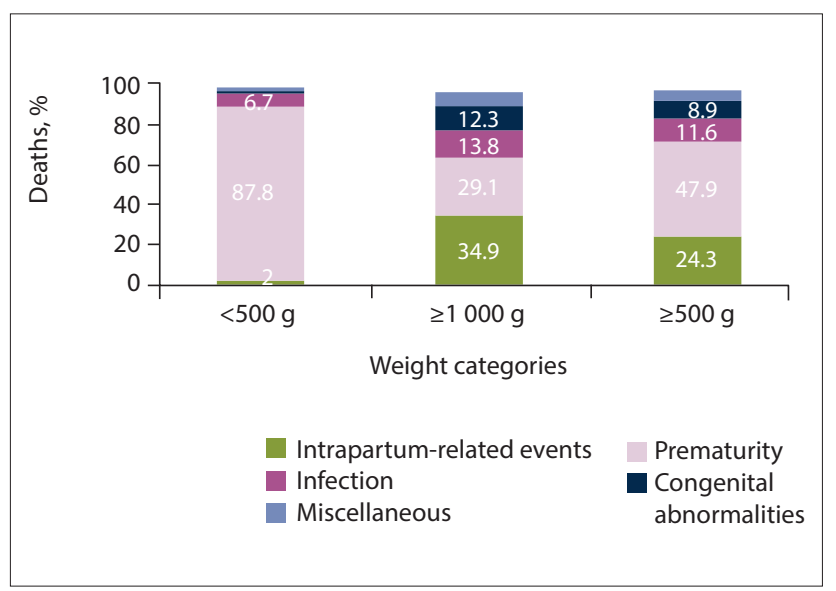

Fig. 3. Cause-specific percentage of neonatal deaths in babies weighing $<500 \mathrm{~g}, \geq 1000 \mathrm{~g}$ and $\geq 500 \mathrm{~g}$ (missing data = unknown cause).

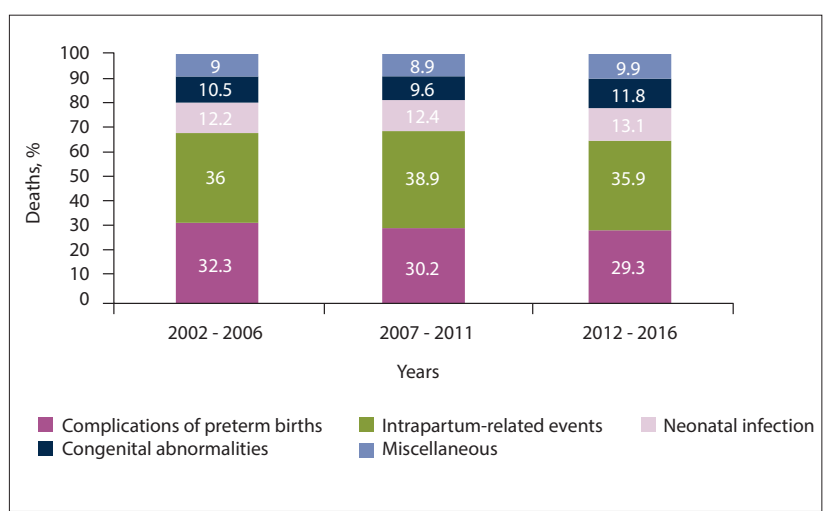

Fig. 4. Cause-specific percentage of neonatal deaths in babies $>1 \mathrm{~kg}$ for three 5-year cohorts.

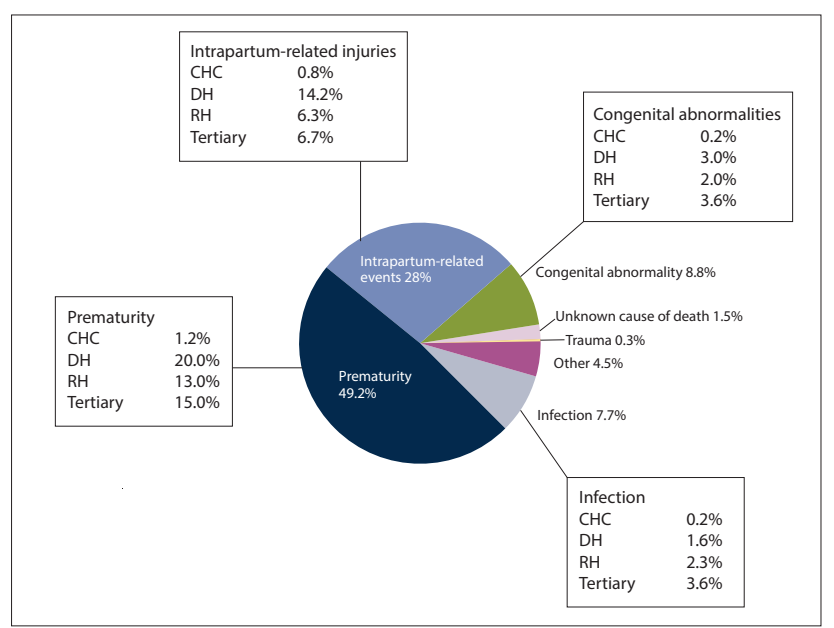

Fig. 5. Causes of neonatal deaths per level of care $(\mathrm{CHC}=$ community health centre; $D H=$ district hospital; $R H=$ regional hospital).

\section{Avoidable factors identified in neonatal deaths}

The top three causes of neonatal deaths have remained the same since 2012. ${ }^{[32]}$ Table 2 shows the top 10 probably avoidable healthsystem-related factors for neonatal deaths, and includes those related to medical personnel, and administrator-related factors. A total of 3 105 neonatal deaths could probably have been avoided, of a total of 12192 deaths.

\section{Strategies and programmes to improve neonatal outcomes}

In 2010, 5 years from the MDG deadline, SA was not on track to achieve MDG 4, the reduction of child mortality, of which neonatal mortality is a key component and the most difficult area to influence. The NDoH, with high ministerial political commitment, embarked on a range of initiatives to reduce neonatal mortality. These included the appointment of a neonatal-care improvement advisor, and the subsequent establishment of the National Neonatal Co-ordinating Committee (NNCC) in 2013, which provided a forum within the $\mathrm{NDoH}$ to co-ordinate and give oversight to improvements in newborn care in SA. Fig. 6 highlights the multitude of initiatives embarked upon since 2008 to improve care across the continuum. The NNCC's main function was to ensure linkage and synergy in terms of the targets, goals, objectives and tasks of these national strategies, plans and campaigns.

The National Perinatal Morbidity and Mortality Committee (NaPeMMCo) made its recommendations for the 2008 - 2010 triennium $^{[3]}$ on saving babies. They are summarised as HHAPINeSS, where HHAPI is an acronym used to summarise the key recommendations needed to improve newborn care and neonatal survival. The acronym is derived from the following:

- Improve the Health system for mothers and babies

- Improve the skills of Healthcare providers in maternal and neonatal care

- Reduce deaths due to Asphyxia

- Reduce deaths due to Prematurity

- Reduce deaths due to Infection.

The implementation of interventions for each of the recommendations formed the basis of the newborn survival strategy (NeSS).

In 2014, NaPeMMCo and the Limpopo Initiative for Newborn Care finalised priority actions for newborn care for the country.

Table 2. Top 10 probably avoidable healthcare-system-related factors and number of deaths, $2014-2015$ (PPIP) $(N=3$ 105) (unpublished ministerial report, $\mathrm{NDoH}$ )

\begin{tabular}{ll}
\hline Modifiable factor & $n$ \\
\hline $\begin{array}{l}\text { Inadequate facilities/equipment in neonatal unit/ } \\
\text { nursery }\end{array}$ & 617 \\
$\begin{array}{l}\text { Nosocomial infection } \\
\text { Fetal distress not detected intrapartum; fetus }\end{array}$ & 423 \\
monitored & 417 \\
$\begin{array}{l}\text { Delay in referring patient for secondary/tertiary } \\
\text { treatment }\end{array}$ & 337 \\
No accessible neonatal ICU bed with ventilator & 306 \\
Neonatal care: management plan inadequate & 288 \\
Neonatal care: inadequate monitoring & 254 \\
Insufficient nurses on duty to manage the patient & 167 \\
adequately & \\
Lack of transport - home to institution & 148 \\
Lack of transport - institution to institution & 148 \\
NDoH = National Department of Health; ICU = intensive-care unit. &
\end{tabular}


The neonatal implementation plan aligned the eight high-impact Lives Saved Tool factors, the three targeted interventions to reduce neonatal mortality and the HHAPINeSS Strategy recommendations (internal document; $\mathrm{NDoH}$, personal communication, 2014) (Fig. 7). All provinces aligned their provincial implementation plans for newborns with these priority actions.

In efforts to achieve the above strategies, a number of training programmes have been implemented. These include Helping Babies Breathe (HBB), Management of Sick and Small Newborns (MSSN) and Essential Steps in Managing Obstetric Emergencies (ESMOE). HBB and MSSN are both training programmes to address the high number of deaths due to prematurity and intrapartumrelated events. Between August 2013 and December 2014, the $\mathrm{NDoH}$ capacitated provinces with master trainers for both programmes. The ESMOE Department for International Development-funded training, which has been scaled up in the last 2 years, also now includes $\mathrm{HBB}$ training.

The PPIP data systems provided disaggregated data in weight categories, and one can calculate indicators to monitor the quality of care (see footnote in Table 3). The 9th Saving Babies report ${ }^{[23]}$ showed, for the first time, a positive shift in the quality of care provided at district level (Tables 3 and 4). This trend was maintained for 2014 and 2015.

\section{Discussion}

\section{Neonatal numbers, mortality rates and causes}

SA has several databases or sources that collect information on neonatal deaths, but most of them focus on deaths occurring within healthcare facilities. Outside of such facilities, the number of deaths is largely unknown, and could explain the discrepancy between the NMR of 12 per 1000 reported from the DHIS data, (a facility-based database) and that reported by SADHS (21 per 1000 ), a population-based survey. The latest Committee On Morbidity And Mortality In Children (CoMMiC) report ${ }^{[34]}$ estimates that $45 \%$ of the under- 5 deaths occur outside healthcare facilities. The child death review (CDR) process modelled and rolled out in high income-countries ${ }^{[35]}$ addresses this gap, and SA's 2013 CDR pilot study, at two mortuary sites in KZN and the Western Cape, have shown that $44.3 \%$ of the infant $(<1$ year old $)$ pneumonia deaths were associated with prematurity, with a number of these deaths occurring within 72 hours after discharge from hospital. ${ }^{[36]}$ Therefore quantifying, capturing, analysing

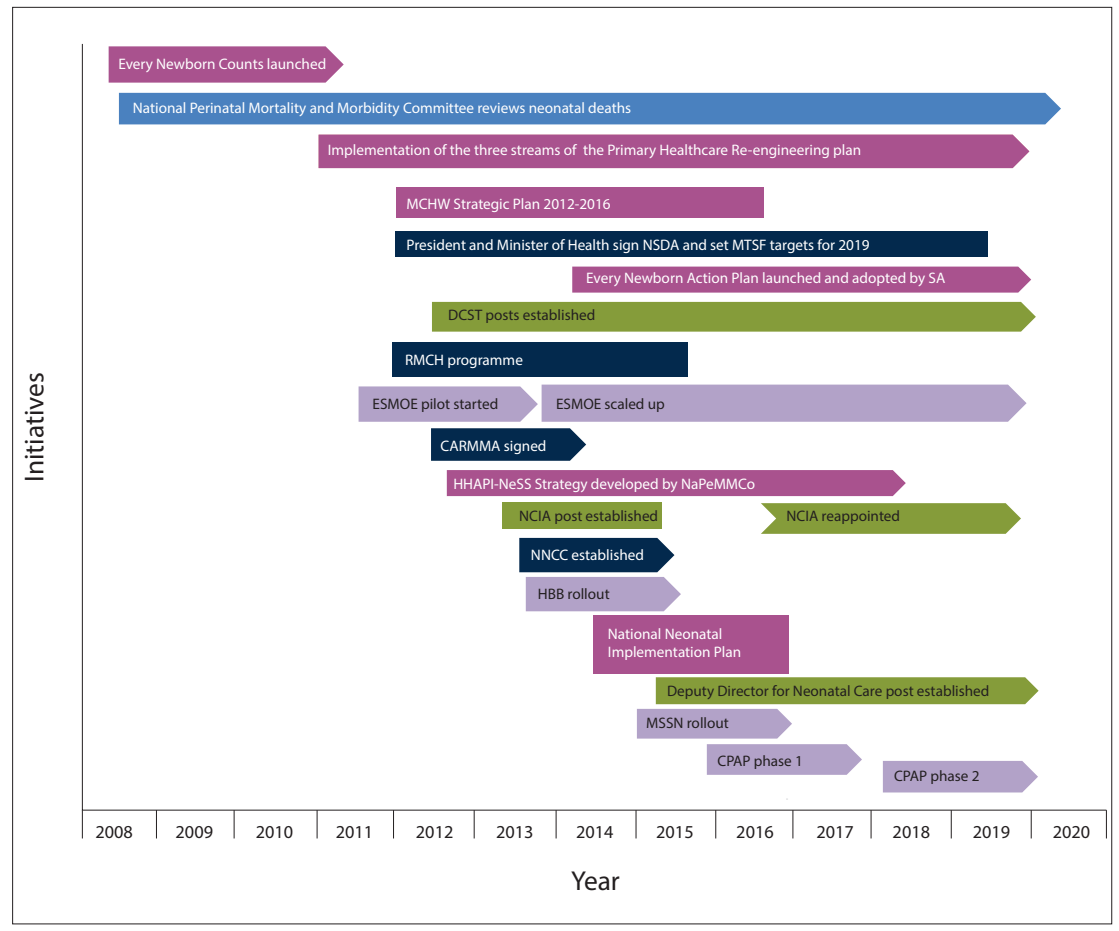

Fig. 6. Initiatives to improve neonatal care. (MCHW = Maternal, Newborn, Child and Women's Health and Nutrition in South Africa 2012 - 2016; NDSA = negotiated service delivery agreement; MTSF = medium-term strategic framework; $S A=$ South Africa; DCST = district clinical specialist team; $R M C H=$ Reducing Maternal and Child Mortality; ESMOE = Essential Steps in the Management of Obstetric Emergencies; CARMMA = Campaign for the Accelerated Reduction of Maternal Mortality in Africa; NCIA - neonatal care improvement advisor; NNCC = National Neonatal Co-ordinating Committee; $H B B=$ Helping Babies Breathe; $M S S N=$ managing small and sick newborns; $C P A P=$ continuous positive airway pressure.)

\begin{tabular}{|c|c|}
\hline Recommendation & Interventions \\
\hline $\begin{array}{l}\text { Improve the Health system for } \\
\text { mothers and babies }\end{array}$ & $\begin{array}{l}\text { - Ensure 24-hour access to functioning emergency } \\
\text { obstetric and neonatal care (both basic and comprehensive). } \\
\text { Dedicated ambulances, maternal waiting homes, KMC sites in } \\
\text { all hospitals, etc. } \\
\text { - Ensure accessible and appropriate contraceptive services } \\
\text { for all women, which are integrated into all levels of healthcare } \\
\text { and are available on site for post-miscarriage and postpartum women. }\end{array}$ \\
\hline $\begin{array}{l}\text { Improve the skills of Healthcare } \\
\text { providers in maternal and neonatal care }\end{array}$ & $\begin{array}{l}\text {-Train all healthcare workers involved in maternity and neonatal } \\
\text { care on the ESMOE-EOST programme (including HBB) and in MSSN infants. } \\
\text { - Train all healthcare workers who deal with pregnant women in HIV advice, } \\
\text { counselling, testing and support; and initiation and monitoring of HAART. }\end{array}$ \\
\hline Reduce deaths due to Asphyxia & $\begin{array}{l}\text { - Ensure that labour is monitored appropriately by a skilled birth attendant. } \\
\text { - Ensure that all birth attendants are skilled at a minimum level in neonatal bag } \\
\text { and mask preparation. } \\
\text { - Ensure that the partogram is used to monitor labour and that the fetus } \\
\text { and mother are monitored according to the prescribed norms, ensuring proper } \\
\text { data interpretation. }\end{array}$ \\
\hline Reduce deaths due to Prematurity & $\begin{array}{l}\text { - Ensure that corticosteroids are given to every woman in preterm labour. } \\
\text {-Ensure that antibiotics are given with preterm rupture of membranes. } \\
\text { - Ensure that the appropriate hospitals are skilled in the use of nasal CPAP. } \\
\text { - Ensure that all mothers of immature infants have easy access to KMC. }\end{array}$ \\
\hline Reduce deaths due to Infection & $\begin{array}{l}\text { - Promote breastfeeding (especially exclusive breastfeeding). } \\
\text { - Ensure clean cord care. } \\
\text { - Ensure strict adherence to basic hygiene in labour wards and nurseries. } \\
\text { - Ensure that presumptive antibiotic therapy for at-risk newborns is available. } \\
\text { - Ensure case management of neonatal sepsis, meningitis and pneumonia. }\end{array}$ \\
\hline
\end{tabular}

Fig. 7. The HHAPI-NeSS strategy. (KMC = kangaroo mother care; ESMOE-EOST = essential steps in managing obstetric emergencies and emergency obstetric simulation training; $H B B=$ Helping Babies Breathe; MSSN = managing small and sick newborns; HAART = highly active antiretroviral treatment; CPAP = continuous positive airway pressure. $)$ 
Table 3. Trends in the quality-of-care indicators among newborns weighing $>2.5 \mathrm{~kg}$ per level of care in SA, $2012-2015$ (PPIP)*

\begin{tabular}{|c|c|c|c|c|c|c|c|c|c|c|}
\hline \multirow[t]{2}{*}{ Year } & \multicolumn{2}{|c|}{$\begin{array}{c}\text { Community } \\
\text { health centres }\end{array}$} & \multicolumn{2}{|c|}{ District hospitals } & \multicolumn{2}{|c|}{ Regional hospitals } & \multicolumn{2}{|c|}{ Tertiary hospitals } & \multicolumn{2}{|c|}{$\begin{array}{c}\text { National } \\
\text { central hospitals }\end{array}$} \\
\hline & $\begin{array}{l}\text { PNMR } \\
>2.5 \mathrm{~kg}\end{array}$ & $\begin{array}{l}\text { ENNDR } \\
>2.5 \mathrm{~kg}\end{array}$ & $\begin{array}{l}\text { PNMR } \\
>2.5 \mathrm{~kg}\end{array}$ & $\begin{array}{l}\text { ENNDR } \\
>2.5 \mathrm{~kg}\end{array}$ & $\begin{array}{l}\text { PNMR } \\
>2.5 \mathrm{~kg}\end{array}$ & $\begin{array}{l}\text { ENNDR } \\
>2.5 \mathrm{~kg}\end{array}$ & $\begin{array}{l}\text { PNMR } \\
>2.5 \mathrm{~kg}\end{array}$ & $\begin{array}{l}\text { ENNDR } \\
>2.5 \mathrm{~kg}\end{array}$ & $\begin{array}{l}\text { PNMR } \\
>2.5 \mathrm{~kg}\end{array}$ & $\begin{array}{l}\text { ENNDR } \\
>2.5 \mathrm{~kg}\end{array}$ \\
\hline 2011 & 2.5 & 0.5 & 11.2 & 4.1 & 9.0 & 2.6 & 16.6 & 5.6 & 15.8 & 5.5 \\
\hline 2012 & 3 & 0.8 & 11.1 & 4.1 & 9.9 & 2.9 & 17.6 & 6.2 & 18.7 & 7.8 \\
\hline 2013 & 2.7 & 0.5 & 10.7 & 4.0 & 10.4 & 3.2 & 15 & 5.0 & 11.6 & 3.3 \\
\hline 2014 & 2.1 & 0.5 & 10.1 & 3.8 & 8.8 & 2.8 & 14.8 & 5.3 & 11.1 & 3.3 \\
\hline 2015 & 2.3 & 0.6 & 9.3 & 3.4 & 9.8 & 3.4 & 16.2 & 6.1 & 12.9 & 2.8 \\
\hline
\end{tabular}

Table 4. Trends in the early neonatal death rates among newborns weighing $1-1.49 \mathrm{~kg}$ per level of care in SA public health facilities, 2012 - 2015 (PPIP)*

\begin{tabular}{|c|c|c|c|c|c|}
\hline Year & $\begin{array}{l}\text { Community health } \\
\text { centres }\end{array}$ & District hospitals & Regional hospitals & Tertiary hospitals & $\begin{array}{l}\text { National central } \\
\text { hospitals }\end{array}$ \\
\hline 2011 & 49.9 & 220.3 & 91.1 & 138.9 & 122.4 \\
\hline 2012 & 32.4 & 228.0 & 113.3 & 149.0 & 100.4 \\
\hline 2013 & 35.0 & 211.5 & 120.8 & 112.0 & 85.4 \\
\hline 2014 & 58.9 & 221.2 & 109.0 & 135.3 & 67.5 \\
\hline 2015 & 47.1 & 213.0 & 124.2 & 180.4 & 40.9 \\
\hline
\end{tabular}

Table 5. Lives saved using the Lives Saved Tool in SA

\begin{tabular}{ll}
\hline The LiST newborn interventions & $\begin{array}{l}\text { Lives } \\
\text { saved, \% }\end{array}$ \\
\hline Antenatal corticosteroids for preterm labour & 12 \\
Labour and delivery management & 10 \\
Prevention of mother-to-child transmission of HIV & 9 \\
Oral rehydrate solution & 9 \\
Handwashing with soap & 7 \\
Case management of severe neonatal infection & 7 \\
Water connection in the home & 5 \\
Antiretroviral treatment & 4 \\
Pneumococcal vaccine & 4 \\
Therapeutic feeding for severe wasting & 4 \\
Treatment of injuries & 4 \\
SA = South Africa; LiST = Lives Saved Tool. &
\end{tabular}

and reviewing these out-of-facility deaths is vital for an overall reduction in the under-5 mortality rate, and especially in the NMR.

Differences in the NMR between the two sources can also be attributed to the definition of the neonatal period: the SADHS uses a postnatal age of 31 days, while the DHIS uses 28 days. Secondly, SADHS data come from questionnaires administered to mothers in the community; therefore, it is possible that the recall of these mothers includes stillbirths. This explanation is informed by a recent Malawian study ${ }^{[37]}$ that found that in contrast, $20 \%$ of neonatal deaths were wrongfully classified as stillbirths after a full birth history by the mother. StatsSA and the MRC will review the SADHS data to confirm whether the SA NMR is double the current DHIS estimates.

The NMR in SA is much higher than that reported in 2013 from developed regions (3.38 per 1000$)$, countries from Eastern Asia (7.69 per 1 000), and Latin America (9.21 per 1 000), but lower than the average of countries (including SA itself) from sub-Saharan Africa (31.1 per 1000), and similar to that reported from North Africa. Within the sub-Saharan countries, only 2 island countries, the Seychelles and Mauritius, have lower NMRs than SA, at 8.82 and 8.90 per 1000 live births, respectively. ${ }^{[38]}$

Unless efforts to reduce NMRs are intensified, there is a high risk of not meeting the global Sustainable Development Goal (SDG) target for the NMR, and the issue of newborn survival remains an unfinished item on the agenda.

The database that reports on the causes of deaths is PPIP, but of major concern is the fact that only four provinces (Mpumalanga, the Western Cape, Limpopo and Free State) have complete PPIP data in relation to the DHIS. Unfortunately, the most densely populated provinces, KZN, Gauteng and the Eastern Cape, have gaps of $>25 \%$ between PPIP and DHIS data, which makes planning and analysis based on causes of death problematic. The Eastern Cape data is of concern, as it shows a $40 \%$ reduction in neonatal deaths, which is unlikely, and preliminary investigations have shown that this reflects poor data collection and not a true reduction in neonatal deaths. After the provincial closure of neonatal units in the early 2000s, the province has now embarked upon the process of reopening them, since 2013

Prematurity is the driver of neonatal deaths in the country, with those born weighing $<1000$ grams (ELBW) contributing significantly to the mortality figures. Therefore, at facility level, the cause-specific mortality rate-per-weight categories offer facilities an opportunity to decide on where best to focus their interventions, and also provide hospitals with the ability to benchmark within a level of care (e.g. district hospitals). The reduction in ELBW deaths lies primarily in the upstream factors of provision of antenatal steroids, and regular antenatal visits, and not necessarily in the building of more neonatal intensive-care units, which require extra qualified staff and 
expensive equipment that requires regular maintenance. Studies in lower-middle-income countries have shown that providing these surviving infants with breastfeeding, kangaroo mother care and basic continuous positive airway pressure (CPAP) are cost-effective ways of reducing mortality. SA is one of the countries with the lowest exclusive breastfeeding rates in the world, and national campaigns are now underway to improve upon this rate. Early initiation of breastfeeding has been shown in random-effects analyses to lower the risks of all-cause neonatal mortality among all live births (relative risk (RR) 0.56 ; 95\% confidence interval (CI) 0.40 - 0.79) and among low birth weight babies (RR 0.58; 95\% CI 0.43 - 0.78), and of infectionrelated neonatal mortality (RR 0.55 ; $95 \%$ CI $0.36-0.84) .{ }^{[39)}$

The reported increase in numbers of late neonatal deaths could be the direct result of better reporting in paediatric and emergency wards, since more facilities are now introducing Child PIP at facility level. The NDoH has recently embarked on an initiative to align the death reporting numbers between the DHIS (where the numbers of deaths are reported), PPIP (where the causes of death, and other pertinent variables such as weight and gestational age, are recorded) and Child PIP. This will help to ensure that in-facility neonatal mortality rates are aligned and as accurate as possible.

\section{Strategies to reduce neonatal deaths}

At the heart of all the policies, plans and programmes developed by the $\mathrm{NDoH}$ and partners has been a commitment to improve the quality of care for mothers and babies, and thereby reduce preventable neonatal deaths. NaPeMMCo highlighted the need to look at and track quality-of-care indications, as well as the impact indicators of neonatal mortality rates. The improvement in quality of care seen at district level is therefore encouraging, as most of the efforts towards improved neonatal care have targeted district hospitals, community health centres and clinics. These efforts may also reflect the early result of input from the district clinical specialist team (DCSTs) within the districts, and the rollout of training programmes such as HBB across the country.

Three interventions, HBB, MSSN and CPAP, were included in the 15 interventions developed by PRICELESS SA (Priority Cost Effective Lessons for Systems Strengthening South Africa) that, when taken to scale, would reduce neonatal mortality sufficiently to achieve SDG 3 by 2030. However, the costs estimated by PRICELESS SA excluded infrastructure development. For example, CPAP as a non-invasive mode of ventilation has been successful worldwide in the management of respiratory distress syndrome in preterm infants. The early neonatal mortality rate is highest in the $<1.5 \mathrm{~kg}$ weight category of preterm babies. However, the provision of the CPAP model critically requires the availability of medical air. The PPIP data have shown a $20 \%$ overall reduction in absolute deaths in babies $>500 \mathrm{~g}$ coded as hyaline membrane disease over the last 5 years. While difficult to ascribe this reduction only to CPAP, a similar trend was seen when CPAP was provided to rural district hospitals in the Western Cape and Limpopo.

HBB and MSSN have been rolled out in all provinces, but the monitoring and evaluation of these training programmes has not been robust, and thus the national coverage is unknown. In contrast, ESMOE training was fully funded, and the pilot sites have shown a $35 \%$ reduction in their NMRs. As ESMOE goes to scale countrywide, a decline in intrapartum-related deaths is expected. This highlights the need to ensure adequate and ongoing funding not only for the implementation of programmes, but importantly, also for monitoring, evaluation and scale-up. The latest PPIP data show a marked reduction in the number of deaths due to a lack of syphilis screening, inadequate resuscitation and insufficiently trained personnel, which might be ascribed to the rollout of the targeted interventions.

Leadership on the issue of neonatal mortality has proved to be lacking at all levels, ${ }^{[40]}$ but is particularly essential at provincial level to effect change. The three provinces with the best quality of provincially co-ordinated newborn care planning and training programmes, Limpopo, KZN and the Western Cape, have created and funded posts to which provincial paediatricians have been appointed. Strong provincial leadership ensures that accountability mechanisms are in place, and restrains unnecessary expenditure. This attracts funding for neonatal care, as both KZN and Limpopo have secured grants for their rollout of provincial neonatal training programmes. Provincial coverage of targeted interventions such as CPAP has been successful in the Western Cape and Limpopo. Care at regional and tertiary levels has shown no improvement. At regional hospitals, this is probably multifactorial, and may reflect the low health levels of the patients received, and not necessarily the quality of care provided. A key aspect of the neonatal implementation plan was to support the development of tailored, evidence-based plans at district level. DCSTs were the drivers of implementation and overall clinical governance, and their leadership role in neonatal care is discussed in the DCST article in this supplement. ${ }^{[4]]}$

\section{Addressing the challenges}

The suggestions below are intended to address some of the challenges in addressing neonatal mortality in SA.

\section{Scale up evidence-based medical interventions to $80 \%$ coverage}

Chola et al's $\mathrm{s}^{[42]}$ modelling has shown that the additional cost of scaling up key maternal, neonatal and child interventions will amount to less than $1 \%$ of the annual national health budget, which seems affordable in light of a per capita health expenditure of about USD645.00. If these interventions (e.g. improved case management of severe neonatal infection) achieve 95\% coverage with high quality of care, then the modelling suggests that the NMR could be reduced to 6 per 1000 live births. ${ }^{[42]}$

\section{Increase usage of antenatal steroid in preterm labour}

In SA, $22.5 \%$ of perinatal deaths are due to spontaneous preterm labour. Despite a $96 \%$ facility birth rate, there is only $25 \%$ antenatal steroid (ANS) coverage. This is similar to that of Brazil prior to 2014, when it embarked on a national ANS scale-up campaign. A similar effort will enable SA to fully implement a newly developed national guideline that enables midwives to prescribe the first dose of ANS on confirmation of preterm labour. Provision of ANS will make the greatest difference in saving the number of newborn lives (12\%) if coverage increases from the current estimated baseline of $20-40 \%{ }^{[43)}$

Provide a postnatal care package (including the supportive role of community health workers) in neonatal care

The provision of postnatal care is essential for neonate survival. However, this has not been implemented at scale, owing to capacity constraints. Most of the investments in neonatal health have been at facility level, and the link between hospital and home has not yet successfully been bridged by the primary healthcare wardbased outreach teams (WBOTS). Central to the WBOTS are the community health workers (CHWs), and to date only $45 \%$ of these teams are completed. There is growing evidence that sub-Saharan African countries that have done well at reducing child mortality have invested in CHWs and empowered them with therapeutic roles within their health systems. ${ }^{[4]]}$ This curative role is supported by 
World Health Organization guidelines, a Cochrane review ${ }^{[45]}$ and the integrated community case management strategy. ${ }^{[46]}$ The call is out for $\mathrm{SA}$ to increase the number of CHWs, and to include treatment of the common causes of child deaths (pneumonia and diarrhoea) within their scope of practice.

\section{Conclusions}

Reducing neonatal mortality in lower-middle-income countries is complex, and especially difficult if the preventable causes of death have decreased. A Brazilian cohort study ${ }^{[47]}$ showed that the Brazil NMR did not change for two decades despite improvements in maternal and neonatal care and maternal health-seeking behaviour. They attributed the static NMR to an epidemiological and demographic transition the country was going through, with medicalisation of pregnancy and delivery, rapidly increasing the preterm births and deaths, which then offset the gains made in the better survival rate of term infants.

SA has a double burden of disease driving neonatal mortality; term babies are dying owing to intrapartum-related events, and preterm deaths are linked to related complications. Consistently, however, mortality reviews conducted at facility level have identified that $>50 \%$ of these neonatal deaths are probably avoidable. As most births occur in facilities, the focus should remain on the quality of perinatal and intrapartum care provided by healthcare workers, and the ability of facilities to provide essential emergency and basic neonatal care. SA cannot afford to rapidly increase the capacity of its healthcare workers, but can redistribute and train the existing workforce to deliver better-quality care. This will require that accountability mechanisms are enforced by all managers at all levels to achieve a faster annual rate of reduction in NMR.

We need to continue to improve upon existing infrastructure, ensure the sustainability of the health system gains and intensify efforts to achieve $95 \%$ coverage of the $15 \mathrm{LiST}$ interventions currently being costed by $\mathrm{NDoH}$ (Table 5). This should help to ensure that the appropriate resources and evidence-based interventions in improving neonatal care are made available in all public healthcare facilities. Underpinning all these efforts is the improvement in the quality of the data available, with attention to modifiable factors in out-of-facility deaths. Plans are afoot by the $\mathrm{NDoH}$ to synchronise and align PPIP and Child PIP with the DHIS. This will reduce data duplication, and hopefully allow for easier institutionalisation of these programmes. The investments made by the $\mathrm{NDoH}$ in system strengthening, by providing leadership in policies and placing an emphasis on doing the basics right, should enable SA to achieve the SDG for the NMR by 2030.

Acknowledgements. We would like to acknowledge Dr Debbie Bradshaw (SA MRC Burden of Disease Unit) and Prof. Bob Pattinson (SA MRC Maternal and Infant Health Care Strategies Research Unit).

Author contributions. NRR, SV, GSG and SK conceptualised the paper and co-ordinated the writing process. NRR, GSG and SV were responsible for the analysis and figures. SK and PB reviewed the manuscript. All authors contributed to article drafts, and approved the final manuscript.

Funding. None

Conflicts of interest. None

1. Lawn JE, Cousens S, Zupan J. 4 million neonatal deaths: When? Where? Why? Lancet 2005;365(9462):891 900. https://doi.org/10.1016/S0140-6736(05)71048-5

2. Knippenberg R, Lawn JE, Darmstadt GL, et al. Systematic scaling up of neonatal care in countries. Lancet 2005;365(9464):1087-1098. https://www.ncbi.nlm.nih.gov/pubmed/15781104 (accessed 9 February 2018).

3. Liu L, Oza S, Hogan D, et al. Global, regional, and national causes of under-5 mortality in 2000 -15: An updated systematic analysis with implications for the Sustainable Development Goals. Lancet 2016;388(10063):30273035. https://doi.org/10.1016/S0140-6736(16)31593-8
4. Lawn J, Blencoew H, Kinney MV, Bianchi F, Graham WJ. Evidence to inform the future for maternal and newborn health. Best Pract Res Clin Obstet Gynaecol 2016;36:169-183. https://doi.org/10.1016/j. bpobgyn.2016.07.004

5. Joubert J, Rao C, Bradshaw D, Dorrington RE, Vos T, Lopez A. Characteristics, availability and uses of vital registration and other mortality data sources in post-democracy South Africa. Glob Health of vital registration and other mortality data sources in post-d

6. Dorrington RE, Bradshaw D, Laubscher R, Nannan N. Rapid Mortality Surveillance Report

Dorrington RE, Bradshaw D, Laubscher R, Nannan N. Rapid Mortality Surveillance Report
2015. Cape Town: South African Medical Research Council, 2016. http://www.mrc.ac.za/bod/ 2015. Cape Town: South African Medical Research Council, 2016.
RapidMortalitySurveillanceReport2015.pdf (accessed 9 February 2018).

7. Dorrington RE, Bradshaw D, Laubscher R, Nannan N. Rapid Mortality Surveillance Report 2014. Cape Town: South African Medical Research Council, 2015. http://www.mrc.ac.za/bod/ RapidMortalitySurveillanceReport2014.pdf (accessed 9 February 2018).

8. Dorrington RE, Bradshaw D, Laubscher R, Nannan N. Rapid Mortality Surveillance Repor 2013. Cape Town: South African Medical Research Council, 2014. http://www.mrc.ac.za/bod/ RapidMortalitySurveillanceReport2013.pdf (accessed 9 February 2018).

9. Dorrington RE, Bradshaw D, Laubscher R. Rapid Mortality Surveillance Report 2012 Cape Town: South African Medical Research Council, 2014. http://www.mrc.ac.za/bod/ RapidMortalitySurveillanceReport2012.pdf (accessed 9 February 2018).

10. Statistics South Africa. Perinatal deaths in South Africa, 2014. Pretoria: StatsSA, 2014. http://www. statssa.gov.za/publications/P03094/P030942014.pdf (accessed 27 October 2016).

11. Statistics South Africa Perinatal deaths in South Africa, 2011 - 2013. Pretoria: StatsSA, 2015. http:// www.statssa.gov.za/publications/P03094/P030942013.pdf (accessed 9 February 2018),

12. National Department of Health, Statistics South Africa, South African Medical Research Council, ICF [International Classification of Functioning, Disability and Health]. South African Demographic and Health Survey 2016: Key Indicators. Pretoria, South Africa and Rockville, Maryland, USA: NDoH, StatsSA, SAMRC, ICF, 2017. http://www.statssa.gov.za/publications/Report\%2003-00-09/Report\%20 03-00-092016.pdf (accessed 9 February 2018).

13. Department of Health, Medical Research Council, ORC Macro, South Africa. Demographic and Health Survey 2003. Pretoria: Department of Health, 2007. https://dhsprogram.com/publications/ publication-fr206-dhs-final-reports.cfm (accessed 9 February 2018).

14. Department of Health, Medical Research Council. South Africa Demographic and Health Survey 1998. Pretoria: DoH, 2001. http://www.mrc.ac.za/bod/SADHS1998FullReport.pdf (accessed 9 February 2018).

5. Pattinson R, PPIP Group. Saving babies 2000: First report on perinatal care in South Africa. Pretoria: Tshepesa Press, 2014. https://www.ppip.co.za/wp-content/uploads/Saving-babies-2000.pdf (accessed 9 February 2018).

16. Pattinson R, PPIP Group. Saving babies 2001: Second report on perinatal care in South Africa. Pretoria: Tshepesa Press, 2014. https://www.ppip.co.za/wp-content/uploads/Saving-babies-2001.pdf (accessed 9 February 2018).

17. Pattinson R, PPIP Group. Saving babies 2002: Third report on perinatal care in South Africa. Pretoria: Tshepesa Press, 2014. https://www.ppip.co.za/wp-content/uploads/Saving-babies-2002.pdf (accessed 9 February 2018).

18. Pattinson R, PPIP Group. Saving babies 2003: Fourth report on perinatal care in South Africa. Pretoria: Tshepesa Press, 2014. https://www.ppip.co.za/wp-content/uploads/Saving-babies-2003.pdf (accessed 9 February 2018).

19. Pattinson R, PPIP Group. Saving babies 2003 - 2005: Fifth report on perinatal care in South Africa. Pretoria: Tshepesa Press, 2014. https://www.ppip.co.za/wp-content/uploads/Saving-Babies-2003-5.pd (accessed 9 February 2018).

20. Pattinson R, PPIP Group. Saving babies 2006 - 2007: Sixth report on perinatal care in South Africa. Pretoria: Tshepesa Press, 2014. https://www.ppip.co.za/wp-content/uploads/Saving-babies-2006-7.pdf (accessed 9 February 2018).

21. Pattinson R, PPIP Group. Saving babies 2008 - 2009: Seventh report on perinatal care in South Africa. Pretoria: Tshepesa Press, 2014. https://www.ppip.co.za/wp-content/uploads/Saving-Babies-2008-9.pdf (accessed 9 February 2018).

22. Pattinson R, PPIP Group. Saving babies 2010 - 2011: Eighth report on perinatal care in South Africa Pretoria: Tshepesa Press, 2014. https://www.ppip.co.za/wp-content/uploads/Saving-Babies-2010-2011. Pretoria: Tshepesa Press, 2014.
pdf (accessed 9 February 2018).

23. Pattinson P, Rhoda N, PPIP Group. Saving babies 2012-2013: Ninth report on perinatal care in South Africa. Pretoria: Tshepesa Press, 2014. https://www.ppip.co.za/wp-content/uploads/SavingBabies-2012-2013.pdf (accessed 9 February 2018).

24. A Krug, RC Pattinson, editors. Saving Children 2004: A survey of child healthcare in South Africa Pretoria: MRC Research Unit for Maternal and Infant Health Care Strategies, 2006. http://www.childpip. org.za/images/stories/documents/report_saving_children_2004.pdf (accessed 9 February 2018).

25. ME Patrick, CR Stephen, editors. Saving Children 2005: A survey of child healthcare in South Africa, Pretoria, 2007. http://www.childpip.org.za/documents/report_saving_children_2005.pdf (accessed 9 February 2018).

26. CR Stephen, ME Patrick, editors. Saving Children 2006: A survey of child healthcare in South Africa. Pretoria: University of Pretoria, MRC, CDC, 2008 http://www.childpip.org.za/documents/report saving_children_2006.pdf (accessed 9 February 2018).

27. CR Stephen, MC Mulaudzi, S Kauchali, ME Patrick eds. Saving Children 2005 - 2007: A fourth survey of child healthcare in South Africa. Pretoria: University of Pretoria, MRC, CDC, 2009 http://www. childpip.org.za/images/stories/documents/Saving Children_2005 2007.pdf (accessed 9 February 2018).

28. Stephen CR, Bamford LJ, Patrick ME, Wittenberg DF, editors. Saving Children 2009: Five Years of Data. A sixth survey of child healthcare in South Africa. Pretoria: Tshepesa Press, MRC, CDC, 2011. Data. A sixth survey of child healthcare in South Africa. Pretoria: Tshepesa Press, MRC, CDC,
http://www.childpip.org.za/documents/saving_children_2009.pdf (accessed 9 February 2018).

29. Stephen CR, Bamford LJ, editors. Saving Children 2010 - 2011: A seventh survey of child health care in South Africa. Pretoria: Tshepesa Press, MRC, CDC, 2013 http://www.childpip.org.za/images/stories/ saving_children_2010-2011.pdf (accessed 9 February 2018).

30. CR Stephen, editor. Saving Children 2012-2013: An eighth survey of child healthcare in South Africa. Pretoria: Tshepesa Press, 2016 http://www.childpip.org.za/images/stories/documents/saving children_2012-2013.pdf (accessed 9 February 2018).

31. Moxon SG, Ruysen H, Kerber KJ, et al. Count every newborn; a measurement improvement roadmap for coverage data. BMC Pregnancy Childbirth 2015;15(Suppl 2):S8 https://doi.org/10.1186/1471-2393$15-\mathrm{S} 2$-S8

2. Velaphi S, Rhoda N. Reducing neonatal deaths in South Africa - are we there yet, and what can be done? S Afr J Child Health 2012;6(3):67-71. https://doi.org/10.1186/1471-2393-15-S2-S8

33. National Perinatal Morbidity and Mortality Committee. National Perinatal Mortality and Morbidity Committe (NaPeMMCo) Triennial Report (2008 - 2010). Pretoria: National Department of Health, 2011

National Department of Health. 2nd Triennial Report of the Committee on Morbidity an Mortality in Children under 5 Years (CoMMiC): 2014 (Abridged version). Pretoria: NDoH, 2014. http://www. kznhealth.gov:za/mcwh/2nd-CoMMiC-Triennial-Report-Abridged.pdf (accessed 9 February 2018).

35. Fraser J, Sidebotham P, Frederick J, Covington T, Mitchell EA. Learning from child death review in the USA, England, Australia, and New Zealand. Lancet 2014;384(9946):894-903. https://doi.org/10.1016/S01406736(13)61089-2

36. Mathews S, Martin LJ, Coetzee D, et al. The South African child death review pilot: A multiagency approach to strengthen healthcare and protection for children. S Afr Med J 2016;106(9):895-899. https://doi.org/10.7196/ SAMJ.2016.v106i9.1123 
37. Liu L, Kalter D, Chu Y, et al. Understanding misclassification between neonatal deaths and stillbirths: Empirical evidence from Malawi. PLOS ONE 2016;11(12):e0168743. https://doi.org/10.1371/journal.pone.0168743 Liu L, Oza S, Hogan D, et al. Global, regional, and national causes of child mortality in 2000 - 13, with projections to inform post-2015 priorities: An up

3. Debes AK, Kohli A, Walker N, et al. Time to initiation of breastfeeding and neonatal mortality and morbidity Bio Med Central Public Health 2013;13(Suppl 3):S19. https://doi.org/10.1186/1471-2458-13-S3-S19

. National Department of Health, South Africa. National Report for the Mid-Term Review of the Strategic Plan for Maternal, Newborn, Child and Women's Health (MNCWH) and Nutrition in South Africa November 2015. Pretoria: NDoH, 2015. http://www.emtct-thelastmile.co.za/wp-content/uploads/2016/07/Mid-Term-

review-report-MNCWH.pdf
41. U Feucht, $\mathrm{C}$ Marshall, $\mathrm{S}$ Kauchali, et al. Innovations in the clinical care of mothers and children in South Africa: The contribution of district clinical specialist teams. S Afr Med J 2018;108(Suppl 1):S38-S43.

. Chola L, Pillay Y, Barron P, Tugendhaft A, Kerber K, Hofman K. Cost and impact of scaling up intervention 2015;8(1):27265. https://doi.org/10.3402/gha.v8.27265

.

Afr. Afr Med J 2013:103(8):518-519. https//doi.org/10.7196/SAMJ.7200
44. Doherty T, Kroon M, Rhoda N, Sanders D. Ending preventable child deaths in South Africa: What role can ward-based outreach teams play? S Afr Med J 2016;106(7):672-674. https://doi.org/10.7196/ role can ward-based outrec

45. Lassi ZS, Haider BA, Bhutta ZA. Community-based intervention packages for reducing maternal and neonatal morbidity and mortality and improving neonatal outcomes. Cochrane Database Syst Rev 2010;10(11):CH007754. https://doi.org/10.1002/14651858.CD007754.pub3

46. Rasanathan K, Muñiz M, Bakshi S, et al. Community case management of childhood illness in subSaharan Africa - findings from a cross-sectional survey on policy and implementation. J Glob Health 2014;4(2):020401. https://doi.org/10.7189/jogh.04.02040

47. Barros FC, Victora CG, Barros AJD, et al. The challenge of reducing neonatal mortality in middleincome countries: Findings from three Brazilian birth cohorts in 1982, 1993, and 2004. Lancet 2005;365(9462):847-854. https://doi.org/10.1016/S0140-6736(05)71042-4

Accepted 12 September 2017. 